\title{
Investigation on the Present Situation of Experimental Skills Competition in Local Medical Universities
}

\author{
Qi-Tao LIU ${ }^{\mathrm{a}}$, Min CHENG ${ }^{\mathrm{b}^{*}}$ \\ Department of Educational Administration, Weifang Medical University \\ ashyglk@wfmc.edu.cn \\ *Corresponding author: Min CHENG
}

Keywords: Experimental skills competition, Investigation and study, Innovative cultivation.

\begin{abstract}
In order to strengthen the training of students' experimental skills, the school held more than 30 experimental skills competitions every year. In order to understand the status of competition, the school conducted a questionnaire survey on the organization of skills competition. The results show that the students are relatively satisfied with the organization process, content design and effect of the experimental skills competition, and the enthusiasm of participating in the competition is relatively high, and the experimental skills competition has achieved ideal results. At the same time, the survey also found that part of the competition content in training students' innovative thinking and innovation ability and other aspects of the urgent need to strengthen.
\end{abstract}

\section{Introduction}

Medicine is a practical science, and the training of clinical ability is the core of medical education. But once, medical practice education has become a short board in the medical education of our country. In 2010, the National Medical College Students' clinical skills competition broke through the ice and explored and promoted the reform of medical personnel training mode and clinical practice teaching[1]. Our school has three consecutive teams participating in the National Medical College Students' clinical skills competition, and won the two prize in the national finals.

In the summary of the successful experience of the competition, our school also aims to explore and promote the experimental skills competition in the school for the shortcomings and shortcomings of this kind of high level competition in the training of local medical colleges and universities[2]. In recent years, the experimental skill competition of our school has developed vigorously. More than 30 competitions are held every year. The quality of the competition has been greatly improved. The competition content is from the original single subject to the present multidisciplinary organization. It can cover 23 major schools, including clinical medicine, nursing and pharmacy, all the students in the 1-5 year level, and the school "whole course" The hierarchical competition system has been gradually formed.

However, because the skills competition is mainly carried out by the various departments and laboratories in combination with the actual situation, the competition's registration, selection, content and evaluation methods are different, and the quality of the competition may be uneven. In order to fully understand the current situation of the school competition, to further improve the quality of competition and to promote the effective integration of competition and teaching, the school carried out a questionnaire survey on the development of experimental skills competition.

\section{Objects and Methods of Investigation}

\section{Object of Investigation}

The survey subjects were selected by stratified sampling, taking into account the types and levels of the test skills competition, the majors and grades of the students participating in the competition, and taking a questionnaire survey of 172 students with representative participation in the competition. Some students who did not enter the competition were interviewed by random interviews. 


\section{Investigation Method and Content}

A self-designed questionnaire was used to conduct anonymous surveys of students. A total of 172 questionnaires were distributed, 164 valid questionnaires were collected, and the effective rate was 95.3\%.

The contents of the survey mainly include 24 aspects: competition organization and registration, competition system design and content, competition results and results, and so on. 3 aspects.

\section{Results and Analysis of Investigation}

\section{Competition Organization and Registration}

Is it necessary to investigate the development of College Students' experimental skills competition? When the school should support competition activities, $96.3 \%$ of the respondents chose "necessary, support", and only 3.7\% chose "no need" or "not to say", indicating that students are supporting and hoping to carry out a skill competition in schools. The results of the study on the initiative of students to enter the competition also proved this: $82.9 \%$ "actively respond to and sign up", and 96.9\% of the respondents considered their participation in the competition and the selection procedure "very reasonable" or "more reasonable".

Of course, there are also some respondents who believe that the registration and organization of the skills competition need to be improved, and even more, when asked about "the way and the selection procedure of the contestants in this skill competition, whether the excellent students have the opportunity to participate", only 36.9\% of the respondents selected "yes" for the individual competition. And some unregistered interviewees also think that their registration and selection methods are not ideal. It is obvious that some of the competition activities need to be revised and perfected in the aspects of guiding students to sign up and selecting excellent students.

\section{Design and Content of the System}

All respondents chose "very reasonable, very satisfactory" or "more reasonable, more satisfactory" while investigating "your evaluation and satisfaction of the design of the competition design of the experimental skill competition", but only $24.4 \%$, "very reasonable, very satisfactory", was chosen because "you think this time" The design of the competition system of the skill competition (such as the first, the reply, the answer, and so on), is it able to ensure that $46.3 \%$ of the participants, especially the excellent players, have chosen "no" or "not necessarily", that they think the competition design of the competition should be more scientific. It is reasonable.

In the investigation of the content of the competition, $82.9 \%$ thought that "the comprehensive application of the classroom experiment" or "the creative content that tends to be higher than the classroom project" reflects the comprehensiveness and innovation of the skill competition. 82.9\% of the respondents believed that the competition content was "moderate in difficulty", but the investigation showed that there were certain differences in the evaluation of different competitions. The reasons may be related to whether the competition content is difficult to be related to, and whether the pre competition guidance is related to the competition. After the investigation, some of the competitions have been systematically coaching before the match, and some are completely failed. There is guidance training, of course, and this competition focuses on the ability of students to investigate [3-4].

\section{Result and Effect of Competition}

The survey shows that most of the respondents are satisfied with the fairness of the competition, but they think that the correlation between the results of the competition and the academic achievement is not very big. It is only $38.4 \%$ that the competition results are directly proportional to the academic achievement and the relationship is close. The rationality of the survey results requires us to conduct in-depth research and exploration from the main points of competition, competition system design and result evaluation.

For the effect of experimental skill competition, we evaluate the following 7 dimensions: To 
review and consolidate the content learned in the classroom, to improve the interest and enthusiasm of the experimental study, to improve the professional skills or to enhance the hands-on ability, to enhance the ability to analyze and solve problems, to exercise innovative thinking and innovation ability, and to cultivate the spirit of team cooperation. And get honorary certificates to increase merit and employment chips. For the above 7 dimensions, according to the obvious benefit of the participants' subjective experience, each dimension is divided into 5 grades, which are very obvious, obvious, obvious, slightly obvious, and very indistinct.

The results of the survey show that the students think that the competition is relatively beneficial in the 3 dimensions of "reviewing and consolidating the contents of the class", "improving the interest and enthusiasm of the experimental learning", "improving the professional skills or enhancing the hands-on ability", and the ratio of "very obvious" or "more obvious" is $80.5 \%, 84.8 \%$, and $88.4 \%$, respectively. The ability to enhance analysis and problem solving as a "very obvious" account for 77.4, and the effect is relatively satisfactory. Although the results of the 2 dimensions of "training team spirit" and "obtaining honorary certificates to increase excellence and employment chips" are not ideal, it is possible to explain that because some competitions focus on students' personal practical skills or innovative abilities, team cooperation is less; and the honor certificates obtained by the competition are still in the short term. It did not materiality in such aspects as appraising merit and evaluating employment and so on. The most important thing to pay attention to is the role of the competition in the "creative thinking and innovation ability". The findings of this dimension show that only $61.6 \%$ of the respondents choose "very obvious" or "more obvious". The results of the evaluation of the competition effect are shown in Table 1.

Table 1

\begin{tabular}{|l|l|l|l|l|l|}
\hline \multicolumn{1}{|c|}{ Benefit evaluation } & 1 level & 2 level & 3 level & 4 level & 5 level \\
\cline { 2 - 7 } Benefit dimension & $\begin{array}{l}\text { Clear as } \\
\text { daylight }\end{array}$ & $\begin{array}{l}\text { More } \\
\text { obvious }\end{array}$ & $\begin{array}{l}\text { Generally } \\
\text { obvious }\end{array}$ & $\begin{array}{l}\text { Slightly } \\
\text { obvious }\end{array}$ & $\begin{array}{l}\text { Not } \\
\text { obvious }\end{array}$ \\
\hline $\begin{array}{l}\text { Review and consolidate the contents } \\
\text { of the class }\end{array}$ & 40.2 & 40.2 & 12.8 & 5.5 & 1.2 \\
\hline $\begin{array}{l}\text { Improving the interest and } \\
\text { enthusiasm of experimental study }\end{array}$ & 47.6 & 37.2 & 12.8 & 1.8 & 0.6 \\
\hline $\begin{array}{l}\text { Improve professional skills or } \\
\text { enhance hands-on ability }\end{array}$ & 55.5 & 32.9 & 7.9 & 3.0 & 0.6 \\
\hline $\begin{array}{l}\text { Enhance the ability to analyze and } \\
\text { solve problems }\end{array}$ & 34.8 & 42.7 & 16.5 & 4.3 & 1.8 \\
\hline $\begin{array}{l}\text { Exercise innovative thinking and } \\
\text { creative ability }\end{array}$ & 27.4 & 34.1 & 25.0 & 11.6 & 1.8 \\
\hline $\begin{array}{l}\text { Training the spirit of team } \\
\text { cooperation }\end{array}$ & 32.3 & 25.0 & 21.3 & 14.0 & 7.3 \\
\hline $\begin{array}{l}\text { Gain a certificate of honor, increase } \\
\text { evaluation, job preparation }\end{array}$ & 21.3 & 33.5 & 23.8 & 15.9 & 5.5 \\
\hline
\end{tabular}

From the results of the students' benefit, we can see that the experimental skill competition held in our school has a slight effect on the cultivation of innovation ability relative to the consolidation of knowledge, the promotion of interest and the enhancement of skills. This reminds us that we should pay more attention to competition in organizing experimental skills competitions in the future. The test and training of the students' innovative ability.

\section{Thinking and Discussion}

The results show that the students are relatively satisfied with the organizational procedures, the content design and the effect of the experimental skills competition, and the enthusiasm for 
participating in the competition is also higher. According to the competition organization of the school in recent years, it can be seen that in the process of exploring the incentive strategy to activate the interest of the main body of the competition, the selection strategy of the competition project ability and the imperceptible penetrating strategy of the competition process, the competition mode of "full and hierarchical" is gradually formed, and the teachers and students' organizations participate in the competition. The students' learning interest and effect have been improved significantly, and the teaching mode of the integration of competition and education has been gradually formed. The enthusiasm of teachers in the reform of experimental teaching is improved, and the demonstration and radiation effects of the competition are obviously enhanced by[5].

However, the results of the survey also show that the students think that the selection procedures for some of the competitions need to be improved, and the content of the competition needs to be strengthened in the creative thinking and innovation ability of the students. As a local higher medical college, it is necessary to improve the enthusiasm of the main body of the competition ${ }^{[6]}$ in order to build the test skill competition into a brand event and a possible form of achievement. As the main body of participating in the competition, the students should further strengthen the incentive function of the second class credits and the evaluation and evaluation, so as to guide the students to participate in the competition activity[7]. As the main body of the organization competition, the school needs to strengthen the policy support in the aspects of workload subsidies and experimental funds, so as to ensure that teachers organize competition activities and innovate the enthusiasm of high quality competition[8].

\section{Acknowledgements}

Fund project: Key research project of teaching reform in Shandong province's undergraduate universities ( Formulation and practice of training scheme of five-year applied excellent medical talents in local medical universities; Z2016Z017 ). Sponsored by the student affairs branch of Chinese institute of higher education (Research and practice on the cultivation model of humanistic care spirit in modern medical education; LX2012Y196 ).Engineering project of quality and teaching reform in Shandong higher education institutions" Teaching team of functional experimental courses "(2011).

\section{References}

[1] Center for clinical teaching and research of Medical Education Department of the Ministry of education. The Eighth National College of higher medical colleges and universities has successfully held the [EB/OL]. (2017-05-16) [2018-01-29]. http://www.moe.edu.cn/s78/A08/moe_745/201705/t20170516_304765.html.(In Chinese)

[2] WANG Bingnan, LIU Qian, et al. Taking the high level discipline competition as the guide, the construction of university discipline competition system [J].Education Modernization, 2016(29):45-47.(In Chinese)

[3] ZHANG Baoxiang, LIU Rujiang. Application of experimental skills competition in experimental teaching of histology and embryology [J].Chinese Journal of Histochemistry and Cytochemistry,2014,23(3):295-297.(In Chinese)

[4] MENG Xiangying, GAO Fei, et al. On the promotion of laboratory skills competition to the training of medical laboratory professionals [J].Health Vocational Education, 2015,35 (7):38-40.(In Chinese)

[5] LIU Jianming, WANG Yiguang, et al. Comprehensive experimental Competition Promoting Basic Medical Experiment Teaching Reform [J].Basic Medical Education, 2017,19(8):607-609.(In Chinese) 
[6] YANG Jing, LI Huaiyong, et al. Research on college students' innovation ability training mode basing on "one college one competition"activities. Laboratory Science, 2016,19(4):222-225.(In Chinese)

[7] YIN Xiangye, LIU Yao , et al. Exploration of the role of innovative experiment projects in training innovative medical undergraduates [J]. Medical Education Research and Practice, 2017,25(1):45-47.(In Chinese)

[8] LI Jianxia, ZHOU Wenhe, et al. Strengthening Creative Talents Training with the Platform ofExperiment Teaching Demonstration Center[J].Research and Exploration in Laboratory, 2017,36(5):216-218.(In Chinese) 